\title{
The effect of artificial diet on the production of alarm pheromone by Myzus persicae
}

Article

Accepted Version

van Emden, H. F., Dingley, J., Dewhirst, S. Y., Pickett, J. A., Woodcock, C. M. and Wadhams, L. J. (2014) The effect of artificial diet on the production of alarm pheromone by Myzus persicae. Physiological Entomology, 39 (4). pp. 285-291. ISSN 0307-6962 doi: https://doi.org/10.1111/phen.12074 Available at https://centaur.reading.ac.uk/38562/

It is advisable to refer to the publisher's version if you intend to cite from the work. See Guidance on citing.

To link to this article DOI: http://dx.doi.org/10.1111/phen.12074

Publisher: Wiley Blackwell

All outputs in CentAUR are protected by Intellectual Property Rights law, including copyright law. Copyright and IPR is retained by the creators or other copyright holders. Terms and conditions for use of this material are defined in the End User Agreement.

www.reading.ac.uk/centaur 
Central Archive at the University of Reading

Reading's research outputs online 
The effect of artificial diet on the production of alarm pheromone by Myzus persicae

\section{Helmut F. van Emden*, Jane Dingley*, Sarah Y. Dewhirst ${ }^{\dagger}$, John A. Pickett ${ }^{\dagger}$, Christine M. Woodcock ${ }^{\dagger}$ and Lester J. Wadhams ${ }^{\dagger}$}

"School of Biological Sciences, The University of Reading, Reading, Berkshire, RG6 6AS, U.K. and ${ }^{\dagger}$ Department of Biological Chemistry and Crop Protection, Rothamsted Research, Harpenden, Hertfordshire, AL5 2JQ, U.K.

Running head: Artificial diet and aphid alarm pheromone

Keywords: Artificial diet, aphid, acetate, alarm pheromone threshold

\section{Correspondence}

Helmut van Emden (corresponding author), School of Biological Sciences, University of Reading, Reading, Berks., RG6 6AS, UK. Tel: +44 (0)118 3788493, Fax +44 (0)118 9352421, email: h.f.vanemden@ reading.ac.uk 


\section{Abstract}

1 The cornicle secretion of Myzus persicae reared on artificial diet only elicited an alarm response in plant-reared conspecifics after the young aphids had been transferred to plants for 7 days. Acetate in the form of $0.32 \%$ sodium acetate was therefore added to the diet as an early step in synthesis of the alarm pheromone, $(E)-\beta$-farnesene $(\mathrm{EBF})$. The cornicle secretion of diet-reared aphids then elicited an alarm response.

2 However, there was no difference in internal EBF concentration between plant- and diet-reared aphids. Puncturing aphids, either plant- or diet-reared, with a pin showed that both could elicit an alarm response, though it was reduced by half with diet-reared individuals.

3 Although there were no significant differences in the concentration of EBF produced, the total amount in diet-reared aphids was increased, by acetate in the diet, to be similar to that in plant-reared individuals: the size of aphids reared on acetate-supplemented diet was increased and was comparable with those reared on plants. Bioassays with a range of EBF concentrations showed a high threshold for the alarm response.

4. It is concluded that the different size of aphids reared on plants and standard diet results in them secreting, respectively, below and above the response threshold.

\section{Introduction}

The fully-defined artificial diet designed for the peach-potato aphid, Myzus persicae (Sulzer) by Mittler \& Dadd (1962), successfully maintained a culture of this aphid at Reading University, U.K. for over 30 years without any return to plants (van Emden, 
2009). The diet was based on an analysis of the phloem sap exuded from cut stylets of Tuberolachnus salignus (Gmelin) (Hemiptera: Aphididae) feeding on willow (Salix acutifolia Willdenow) (Mittler, 1958), but concentrations of solutes in the final diet were in many cases considerably altered; the liquid uptake by aphids from diet is probably only about one-eighth that from plants (reviewed by Douglas \& van Emden, 2007). Sucrose in the diet is $15 \%$, and although concentrations in phloem vary extensively with time of day and plant organ, $15 \%$ is consistent with Zimmermann \& Ziegler's (1975) compilation of the sucrose concentration in the phloem of 532 plant species in 102 families, where $49 \%$ of the species recorded sucrose in the 10-20\% range. All but 3 amino acids are more concentrated in diet, most by a factor of around ten (Douglas \& van Emden, 2007). The diet was designed solely for culturing the aphid and so contained only 37 ingredients (mainly vitamins and salts in addition to sucrose and amino acids). This limited number of ingredients contrasts with the many more in phloem sap, which may include amides, potassium, auxins, gibberellins, cytokinins, abscisic acid, nucleotide phosphates and proteins, including enzymes (Atwell et al., 1999).

Some ingredients of phloem sap missing in the diet could be used by aphids for activities other than growth and reproduction. One possibility is that some of these ingredients might be required by the aphid to produce behaviour-modifying semiochemicals such as the alarm pheromone, the sesquiterpene hydrocarbon $(E)-\beta$ farnesene (EBF) (Fig. 1) (Bowers et al., 1972: Pickett et al., 2013). When the cornicles of aphids emit droplets as a response to attack by a predator or parasitoid, this very minor component of the secretion initiates dispersive behaviour in neighbouring aphids (Montgomery \& Nault, 1977). The aphids point their antennae forwards, withdraw their stylets and start walking away from their feeding site; they may even fall off the plant. As $\mathrm{EBF}$ is highly volatile, the effect is usually of short duration and aggregations of aphids 
form again within $1 \mathrm{~h}$ (Calabrese \& Sorensen, 1978). The stimulus is relatively nonspecific and many aphids will respond to the release of the pheromone by another species (Kislow \& Edwards 1972).

In this paper, we investigate if artificial diet has an effect on the initiation of an alarm response by plant-reared aphids via the cornicle droplets and the production of EBF. We also investigated the effect of the addition of acetate (as sodium acetate, $\mathrm{C}_{2} \mathrm{H}_{3} \mathrm{NaO}_{2}$ ), a precursor of EBF, to the artificial diet, since the reluctance of diet-reared aphids to produce alarm pheromone in the first experiment might indeed be due to a missing ingredient.

\section{Materials and methods}

\section{Aphid and plant material}

Myzus persicae used for all experiments, other than analysis for EBF and bioassay with synthetic EBF, were taken from long term plant- and diet-reared cultures at the University of Reading. Brassica oleracea L. var. gemmifera Zenker (Brussels sprout) cv. 'Bedford Winter Harvest', was the plant host and both cultures were derived from the same source - a natural invasion of a glasshouse at Reading in 1962, from which the continuous culture on diet had been established in 1976 (van Emden, 2009). By the time chemical analyses were carried out at Rothamsted Research in 2011, the diet culture at Reading had died out (in December 2010), so insecticide susceptible aphids were taken from a long term culture on Brassica rapa L. subsp. pekinensis (de Louriero) G. Olsson (Chinese cabbage), cv. 'Wong Bok', maintained in a controlled environment room at Rothamsted.

\section{Artificial diet}


The recipe used was that of Mittler \& Dadd (1962), following the procedure given by van Emden (2009), which involves changing the diet every few days, usually on Monday, Wednesday and Friday. The diet was used with and without addition of $0.32 \%$ sodium acetate $(\mathrm{w} / \mathrm{v})$. This concentration was chosen after preliminary tests showed that it did not affect acceptance of the diet by $M$. persicae.

Production of cornicle droplets by diet- and plant-reared aphids

Collecting cornicle droplets for the standard bioassay (see below) was often difficult when the aphids had been diet-reared. A separate experiment was therefore carried out to measure the 'readiness' of diet- and plant-reared aphids to produce cornicle droplets when stimulated. For each datum, 20 aphids were stimulated to produce droplets at the tip of the cornicles by applying slight pressure to the dorsum with a pin, in three replicates of the following four treatments: 1) plant-reared aphids (positive control), 2) diet-reared aphids, 3) aphids born on diet but transferred to Brussels sprout plants for seven days to reach the adult stage and 4) aphids born on Brussels sprout plants but transferred to diet for seven days to reach the adult stage. The datum used was the proportion of aphids that produced cornicle droplets.

\section{Pheromone bioassay with cornicle droplets}

Plant-reared M. persicae (6-10 4th instar or young adults) were confined in a $25 \mathrm{~mm}$ diameter clip cage on the underside of a leaf on a Brussels sprout plant. After two days, the clip cage was removed and the leaves were detached and laid flat, with the aphids uppermost, on a piece of hardboard. The leaves were left for $2 \mathrm{~h}$ to ensure that the aphids were settled. The number of aphids was then recorded. 
An adult aphid was taken from the appropriate experimental treatment (see below) and stimulated to produce droplets at the tip of the cornicles by applying slight pressure to the dorsum with a pin. The two droplets were collected on the tip of a small card triangle (6 $\mathrm{mm}$ long and $3 \mathrm{~mm}$ wide at the base) impaled $6 \mathrm{~mm}$ up an entomological pin. If no droplets were produced, the aphid was discarded and a new individual used.

Immediately after the cornicle droplets had been collected, the pin was pushed into the hardboard through the leaf to position the tip of the card triangle $5 \mathrm{~mm}$ above the centre of the colony of plant-reared aphids. After $5 \mathrm{~min}$, the number of aphids remaining within $20 \mathrm{~mm}$ of the point of the card was recorded. The datum used for analysis was the proportion of the number of previously settled aphids moving away.

Each of the ten replicates of this bioassay of plant-reared aphids comprised five treatments as follows: 1) Blank - no cornicle droplets (negative control), or cornicle droplets collected from 2) a plant-reared aphid (positive control), 3) an aphid reared on the standard artificial diet, 4) an aphid born on diet but transferred to Brussels sprout plants for seven days to reach the adult stage, and 5) an aphid reared for seven days on the standard artificial diet supplemented with $0.32 \%$ sodium acetate $\left(\mathrm{C}_{2} \mathrm{H}_{3} \mathrm{NaO}_{2}\right)$.

\section{Bioassay with pheromone from punctured aphids}

A fine entomological pin was attached to the arm of a micromanipulator to the left of a binocular microscope. A leaf was detached from a Brussels sprout plant in the $M$. persicae culture and laid, with the aphids uppermost, under the microscope. The number of aphids in the field of view of the binocular (diameter of $16 \mathrm{~mm}$ ) was counted. An aphid from the appropriate treatment was then picked up with a drop of nail varnish on the blunt end of a half cocktail stick, which was then clamped to the arm of a micromanipulator on the right hand side of the microscope after the nail varnish had dried. 
The micromanipulators were then used to lower the aphid to about $5 \mathrm{~mm}$ above the centre of the field of view and suddenly pierce it with the point of the needle. The number of aphids which disengaged their stylets and moved position in the following 5 min was recorded and the datum used was this number as a proportion.

Twelve replicates of the following three treatments were carried out: 1) Blank the end of the cocktail stick with dried nail varnish only (negative control), 2) a plantreared or 3) a diet-reared aphid was punctured.

\section{Analysis for (E)- $\beta$-farnesene}

One hundred $M$. persicae of various instars were transferred from Chinese cabbage plants to each of 15 feeding chambers containing standard artificial diet and 15 with diet supplemented with $0.32 \%$ sodium acetate. After seven days, 100 adult/4th instar $M$. persicae from both diets, as well as from Chinese cabbage plants, were put into a glass vial and weighed before analysis for EBF. There were seven replicates of the three treatments. Pentane $(1 \mathrm{ml})$ was then added to the vial and the aphids were crushed with a glass rod. The rod was washed with further pentane $(1 \mathrm{ml}$.$) and the combined extract$ filtered through glass wool to remove aphid debris and dried with $\mathrm{MgSO}_{4}$. The filtrate was concentrated to $1 \mathrm{ml}$. under a stream of nitrogen using a volumetric flask, and an

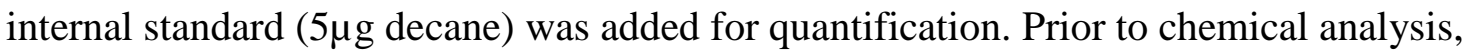
the samples were stored at $-22^{\circ} \mathrm{C}$.

EBF was identified by coupled gas chromatography-mass spectrometry (GC-MS) analysis using a HP 5972 MSD (Mass Selective Detector) and a HP 5890 GC fitted with a non-polar column (HP-1, $50 \mathrm{~m}$ x $0.32 \mathrm{~mm}$ inner diameter x $0.5 \mu \mathrm{m}$ film thickness, $\mathrm{J} \& \mathrm{~W}$ Scientific) and a cool on-column injector (Gerstel TDS3). The GC oven temperature was 
maintained at $40{ }^{\circ} \mathrm{C}$ for $5 \mathrm{~min}$ and then programmed at $5^{\circ} \mathrm{C} \mathrm{min}^{-1}$ to $250{ }^{\circ} \mathrm{C}$. Ionisation was by electron impact at $70 \mathrm{eV}, 250^{\circ} \mathrm{C}$ (source temperature).

The solvent extracts ( $4 \mu 1$.) were analysed by high resolution gas chromatography (GC) on a non-polar (HP-1, $10 \mathrm{~m} 0.53 \mathrm{~mm}$ inner diameter $2.65 \mu \mathrm{m}$ film thickness) capillary column using a HP5890 GC (Agilent Technologies, UK) fitted with a split/splitless injector (splitless mode, $250^{\circ} \mathrm{C}$ ), and a flame ionisation detector (FID). The GC oven temperature was maintained at $30^{\circ} \mathrm{C}$ for 1 min after sample injection and then raised by $5^{\circ} \mathrm{C} \min ^{-1}$ to $150^{\circ} \mathrm{C}$, then $10^{\circ} \mathrm{C} \min ^{-1}$ to $250^{\circ} \mathrm{C}$ and held for $56 \mathrm{~min}$. The carrier gas was hydrogen. Identification of EBF within the extracts was confirmed using peak enhancement by co-injection with a chemical standard (Pickett, 1990). EBF (99\% pure by gas chromatography) was synthesized as stated in Al Abassi et al. (1998). Peak areas for EBF and decane (internal standard) were measured and total EBF content was calculated.

\section{Pheromone bioassay with synthetic (E)- $\beta$-farnesene}

A $1 \mu 1$. droplet of hexane, containing either pure synthetic EBF of known concentration $\left(0.001,0.01,0.1,1,10\right.$ or $\left.100 \mathrm{ng} \mu \mathrm{l}^{-1}\right)$ or neat EBF was placed beside a colony of $5-10$ plant-reared adult $M$. persicae, feeding on leaves of Chinese cabbage. The numbers of aphids responding were counted after $1 \mathrm{~min}$. Three to five replicates were made.

\section{Statistical analysis}

Analysis of variance (ANOVA) for randomised blocks (replicates) was used for the bioassay data. Means were then compared with $t$ tests based on the residual mean square in the analysis. With the data for production of cornicle droplets, a one-tailed test was used to identify lesser responses than shown to the cornicle secretion of plant-reared aphids (positive control). Since there was a lack of response of aphids in the absence of 
pheromone (negative control), a one-tailed test was used for identifying any response. Further validation of differences between the magnitudes of responses was accomplished with a two-tailed test. A 2-tailed test was used with the EBF concentration data following a one-way analysis of variance. A covariance analysis was also carried out on total EBF per aphid when reared on plants, standard diet or diet supplemented with sodium acetate, using mean aphid weight as the dependent variable. The proportion of aphids moving away from synthetic EBF after 1 min was arcsin-transformed and subjected to ANOVA.

\section{Results}

Production of cornicle droplets by diet- and plant-reared aphids (Fig. 2)

The substrate treatments significantly affected the proportion of aphids producing cornicle droplets when artificially stimulated with a pin $\left(F_{3,6}=28.24, P<0.001\right)$. The mean proportion of diet-reared aphids producing droplets was less than a tenth of that in plant-reared aphids $\left(P_{1 \text {-tailed }}<0.001\right)$. Reciprocal transfer between plant and diet caused the aphids to behave as aphids reared only on the destination substrate $\left(P_{2 \text {-tailed }}>0.25\right)$. Thus, transfer from plant to diet caused an $80 \%$ reduction in mean droplet production $(P$ 2-tailed $<0.001)$ and transfer from diet to plant a nine-fold increase $\left(P_{2 \text {-tailed }}<0.001\right)$.

\section{Pheromone bioassay with cornicle droplets (Fig.3)}

The substrate treatments of aphids from which cornicle secretion was obtained significantly affected the proportion of aphids that moved from the vicinity of the secretion when presented on the tip of a card triangle $\left(F_{4,36}=22.95, P<0.001\right)$. In contrast to the mean escape response of over $70 \%$ in plant-reared aphids to the secretion of others that had been plant-reared $\left(P_{1 \text {-tailed }}<0.001\right)$, there was no detectable effect of secretion from diet-reared aphids compared with the blank negative control $\left(P_{1 \text { - tailed }}=1\right)$. 
The secretion of aphids transferred to plants from diet for 7 days did elicit a mean escape response of over 50\% $\left(P_{1 \text {-tailed }}<0.001\right)$, but this was rather lower $\left(P_{2 \text {-tailed }}=0.05\right)$ than the response to the secretion of aphids that had been entirely reared on plants. However, the cornicle secretion of aphids reared on diet supplemented with sodium acetate produced a mean escape response $\left(P_{1 \text {-tailed }}<0.001\right)$ almost as large as that to the secretion of plantreared aphids $\left(P_{2 \text {-tailed }}>0.8\right)$.

\section{Bioassay with pheromone from punctured aphids (Fig. 4)}

There was a significant effect of treatments in the analysis of variance $\left(F_{2,22}=121.56, P\right.$ $<0.001)$. Compared with the blank negative control, the puncturing of aphids, whether plant- or diet-reared, caused an escape response in the bioassayed aphids ( $P_{1 \text {-tailed }}$ $<0.001)$. Moreover, whereas there was a mean escape response of nearly $70 \%$ when the punctured aphid had been plant-reared, puncturing diet-reared aphids elicited a lower mean response of a little under $50 \%\left(P_{\text {2-tailed }}<0.02\right)$.

\section{Analysis for (E)- $\beta$-farnesene (Table 1)}

Mean individual weight was reduced by $25 \%$ in diet-reared compared with plant-reared aphids $\left(P_{2 \text {-tailed }}<0.05\right)$. The concentration of alarm pheromone in the aphid as measured by EBF (ng) aphid (mg)-1 did not differ significantly between the two substrates, but with the smaller diet-reared aphids, the mean total EBF per aphid was reduced by about $30 \% \mathrm{t}$.

These relationships between diet- and plant-reared aphids were changed noticeably when sodium acetate was added to the diet. The aphids were $28 \%$ heavier than when on diet without sodium acetate $\left(P_{2 \text {-tailed }}<0.05\right)$ and were not significantly lower in weight than when plant-reared. Similarly, the total EBF per aphid reared on diet with sodium acetate was not significantly lower than when the aphids were plant-reared, but 
was higher than when reared on the standard diet $\left(P_{2 \text {-tailed }}<0.05\right)$. Again, adding sodium acetate had no effect on the concentration of EBF in the aphids as $\mathrm{ng}^{-1}$. The results of the covariance analysis form part of the Discussion.

Pheromone bioassay with synthetic (E)- $\beta$-farnesene (Fig. 5)

There was a significant effect of treatments in the analysis of variance $\left(F_{6,23}=84.02, P\right.$ $<0.001)$. Compared with the hexane control, EBF at 0.001, 0.1, 1, 10 and $100 \mu \mathrm{g}$, caused a significant escape response in plant-reared aphids. Moreover, a significant higher escape response occurred when 1,10 and $100 \mu \mathrm{g}$ of EBF was present compared to 0.001 and $0.1 \mu \mathrm{g}$ of EBF. There was no significant difference between neat EBF (807 $\mu \mathrm{g})$ and the hexane control.

\section{Discussion}

The hypothesis tested here is that the aphid artificial diet does not provide the ingredients needed for natural activities of aphids other than growth and reproduction. The synthesis of the alarm pheromone $(E)-\beta$-farnesene $(\mathrm{EBF})$ was chosen as the phenomenon by which to test this hypothesis. Our first bioassay showed that, given equal stimulation, only a tenth of diet-reared individuals compared with those plant-reared produced any secretion from their cornicles. Moreover, we have clearly shown that the cornicle secretion of dietreared M. persicae invoked a significantly reduced alarm response in plant-reared conspecifics.

Since it seemed possible that diet-reared aphids might have lost the ability to produce cornicle secretion as an adaptation to what was, at that time, more than 15 years of continuous culture in small tubes, young aphids from diet were transferred back to plants and bioassayed again after a period of 7 days on the plant, by which time they had 
reached the adult instar. Such aphids produced cornicle secretion as readily as continuously plant-reared aphids, and this secretion was effective at alarming other aphids, though the alarm response was significantly less, at only $60 \%$ compared with $75 \%$ for the secretion of plant-reared individuals. Transfer for 7 days in the other direction, i.e. from plant to diet, resulted in the proportion of individuals producing a secretion being just slightly less than that of continuously diet-reared aphids. Thus, it was clear that the low proportion of diet-reared aphids producing cornicle secretion and the failure of such secretion to alarm other aphids was an effect of diet manifesting itself within seven days and not the result of a long-term habituation.

The suggestion at this point was that some ingredient needed for the synthesis of EBF was missing from the diet. It was therefore decided to add chemicals progressively following the metabolic pathway of EBF synthesis, until the aphids regained the ability to alarm others with their cornicle secretion. The addition of acetate was tried first. Sodium acetate $\left(\mathrm{C}_{2} \mathrm{H}_{3} \mathrm{NaO}_{2}\right)$ was used as representing the first stage in the metabolic sequence towards EBF because a preliminary test showed that acetic acid in the artificial diet deterred settling by $M$. persicae (results not shown). The result was dramatic: cornicle secretion from aphids reared on this supplemented diet for 7 days gave almost the same level of alarm response in plant-reared conspecific aphids as secretion from plant-reared ones (respectively 75 and 74\%). However, when we analysed EBF in aphids from plants, from standard diet and from diet supplemented with sodium acetate, the concentration of EBF (as ng mg ${ }^{-1}$ ) in aphids was very similar on all three substrates, with no statistically significant differences between them.

A further hypothesis was therefore that the release rate of EBF from the cornicles of diet-reared aphids was insufficient to elicit an alarm response in other aphids. We attempted to progress using an MS Nose ${ }^{\mathrm{TM}}$ (Micromass - Manchester, UK) developed for 
this type of use at the University of Nottingham (Hollowood et al., 2002). This can be set to detect the presence in the air of a compound from its molecular weight, but proved insensitive to the amount of pheromoe released by plant-reared aphids when these were stimulated to produce cornicle droplets by stroking the abdomen with a fine needle. As one problem might have been that the vessel was open-topped to allow the stimulation of the aphid, we decided to keep the system closed around the sensor of the instrument and introduce a predator to the vessel to provoke cornicle secretion. An adult Anthocoris nemorum (L.) (Hemiptera: Anthocoridae) was found on nettles and, when it punctured the aphid with which it was confined, the trace on the recorder showed a strong peak. That a far larger amount of EBF is released from an aphid when punctured by a predator than is released from the cornicles suggested that puncturing diet-reared aphids, whose cornicle secretion does not elicit an alarm response, might release sufficient amounts of EBF to do so. EBF released from punctured diet-reared aphids proved sufficient to alarm $50 \%$ of other aphids. However, even such sudden release of pheromone through a puncture in the aphid cuticle failed to match the $70 \%$ response with punctured plant-reared aphids.

Although we had found a similar concentration of EBF (as $\mathrm{ng} \mathrm{mg}^{-1}$ body weight) from plant- and diet-reared aphids, the aphids on standard diet were significantly smaller (by 25\%) than plant-reared individuals. Given the similar EBF concentrations, the smaller weight of diet-reared aphids meant that their total EBF content was similarly reduced (actually by about $30 \%$ ). It is logical that it should be the reduction in total EBF of dietreared aphids, rather than the internal concentration, that caused punctured diet-reared aphids to elicit a lower alarm response than when plant-reared. Responding aphids will react to the aerial concentration of EBF they detect, and this will be a function of total content and not concentration in the punctured individual. Clearly, this could mean that the EBF is diluted in the entire body mass of the aphid. However, we suggest that there is 
the same phenomenon operating as with the cornicle droplet and that the lipid body normally forming this droplet is the substrate from which the EBF is released, even when the aphid is punctured. The analysis for EBF also showed that the increase with acetate added to the diet was not due to an increase in EBF concentration, but because aphids on the supplemented diet were no longer smaller than plant-reared ones. They attained $95 \%$ of the plant-reared weight and total EBF content was within $6 \%$ of that of plant-reared aphids.

Contrary to our reason for adding acetate to the diet, the increased alarm reaction caused in the supplemented diet-reared aphids had no connection with the biosynthetic pathway for the pheromone, but was no more than the effect of the addition of the acetate on aphid size. Indeed, when the 21 data points ( 3 substrates $x 7$ replicates) for total EBF content were subjected to covariance analysis with aphid weight as the covariate, the significant variance ratio for substrates $\left(F_{2,18 .}=3.85, P<0.05\right)$ was reduced to just

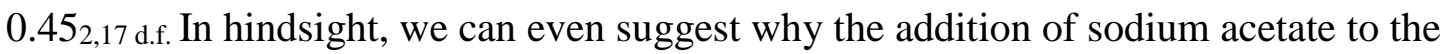
standard diet increased aphid size; the high lipid component of aphid body weight is presumably increased when the direct lipid biosynthesis precursor, acetate, is added to the diet.

If we compare the total amount of EBF in aphids on plants and the standard diet, there was a reduction of only $30 \%$ in diet-reared aphids. This reduction resulted in failure of the cornicle secretion of these aphids to elicit an alarm response in other aphids, but enough to alarm 50\% when the diet-reared aphids were punctured. We have shown (figure 5) that an alarm response only results when the concentration of EBF is rather high and that the pheromone has to be encountered as a sudden 'pulse'. When an aphid is punctured, the 'pulse' condition is fulfilled regardless of whether it is diet- or plant-reared. The significantly lower alarm reaction when a diet-reared aphid is punctured suggests that 
the 30\%reduction in EBF content is close to the response threshold for M. persicae. However, the observations at Nottingham with plant-reared $M$. persicae showed that the MS nose could not identify EBF in cornicle secretion, but reacted strongly when the aphid was punctured. Therefore, since a punctured diet-reared aphid released EBF not far above the response threshold, it is not surprising that its cornicle secretion falls far short.

Evolutionarily, it is surely to be expected that aphids will not synthesise amounts of alarm pheromone greatly in excess of the response threshold, which explains why the efficacy of cornicle secretions will fail with relatively small reductions of EBF content in the body. Moreover, if EBF is synthesised to a fixed amount, this amount is likely to be 'measured' by the aphid in terms of concentration (ng $\mathrm{mg}^{-1}$ body weight) rather than total (ng per aphid). It also appears that aphids are reluctant to secrete EBF from the cornicles if the threshold for the alarm response is not met.

In conclusion, our investigations on alarm pheromone show that we cannot claim that the failure of the cornicle secretion of diet-reared aphids to elicit an alarm response in other aphids is an example of a necessary ingredient missing from the diet. Myzus persicae can clearly synthesise EBF without any addition of sodium acetate; the effect is solely to increase the total amount of EBF in the aphid's body by increasing its size. Fairly recently, two protocols for the $M$. persicae artificial diet have been published (Douglas \& van Emden, 2007; van Emden, 2009). It now seems as if sodium acetate should be included in the recipe for the diet, since it removes the disadvantage of the diet that the aphids are smaller; the performance of $M$. persicae on the diet is therefore likely to be improved.

\section{Acknowledgements}


We are grateful to Elizabeth Wild and the late Thelma Wise for maintaining the artificial culture of M. persicae for so many years. Professor Jim Hardie kindly made his micromanipulator facilities available for the experiment with punctured aphids. Dr Debora Pires from Embrapa Genetic Resource and Biotechnology Biological Control Unit, Brazil, and Dr Ben Webster, Rothamsted Reasearch contributed to the collection and analysis of EBF. Rothamsted Research receives grant-aided support from the Biotechnology and Biological Sciences Research Council (BBSRC) of the United Kingdom.

\section{References}

Al Abassis, S., Birkett, M.A., Pettersson, J., Pickett, J.A. \& Woodcock, C.M. (1998) Ladybird beetle odour identified and found to be responsible for attraction between adults. Cellular and Molecular Life Sciences, 54, 876-879

Atwell, B.J., Kriedemann, P. E. \& Turnbull, G. N. (eds) (1999) Plants in Action. Macmillan, South Yarra, Victoria, Australia.

Bowers, W.S., Nault, L.R., Webb, R.E \& Dutky, S.R. (1972) Aphid alarm pheromone: isolation, identification, synthesis. Science, 177, 1121-1122.

Calabrese, E.J. \& Sorensen, A.J. (1978) Dispersal and recolonisation by Myzus persicae following aphid alarm pheromone exposure. Annals of the Entomological Society of America, 71, 181-182. 
Douglas, A. E. \& van Emden, H. F. (2007) Nutrition and symbiosis. Aphids as Crop Pests (ed. by H.F. van Emden and R. Harrington), pp. 115-134. CAB International, Wallingford, U.K.

van Emden, H. F. (2009) Artificial diet for aphids - thirty years' experience. Redia, 2, 163-167.

Hollowood, T.A., Linforth, R.S.T. \& Taylor, A.J. (2002) The effect of viscosity on the perception of flavour. Chemical Senses, 27, 583-591.

Kislow, C. \& Edwards, L.J. (1972) Repellent odour in aphids. Nature, 235, 108-109.

Mittler, T. E. (1958) Studies on the feeding and nutrition of Tuberolachnus salignus (Gmelin) (Homoptera, Aphididae). II. The nitrogen and sugar composition of ingested phloem sap and excreted honeydew. Journal of Experimental Biology, 35, 74-84.

Mittler T.E. \& Dadd R.H. (1962) Artificial feeding and rearing of the aphid, Myzus persicae (Sulzer) on a completely defined synthetic diet. Nature, 195, 404.

Montgomery, M.E. \& Nault, L.R. (1977) Comparative responses of aphids to the alarm pheromone (E)- $\beta$-farnesene. Entomologia Experimentalis et Applicata, 22, 236-242.

Pickett, J.A. (1990) Gas chromatography-mass spectrometry in insect pheromone identification: three extreme case histories. Chromatography and Isolation of Insect 
Hormones and Pheromones (ed. by A.R. McCaffery and I. D. Wilson), pp. 299-309. Plenum Press, New York and London.

Pickett J.A., Allemann R.K. \& Birkett M.A. (2013) The semiochemistry of aphids. Natural Proucts Report, 30, 1277-1283.

Zimmermann, M. N.. \& Ziegler, N. (1975) Appendix III. List of sugars and sugar alcohols in sieve tube exudates, In: Zimmermann, M.H. and Milburn, J. A. (eds) Encyclopaedia of Plant Physiology, Volume 1. Transport in Plants 1, Phloem Transport. (ed. by M. H. Zimmermann and J. A. Milburn), pp. 480-503. Springer, Berlin. 
Table 1. Analysis of (E)- $\beta$-farnesene in aphids reared on plants, on artificial diet and on diet supplemented with $0.32 \%$ sodium acetate (means of 7 replicates \pm s.e.). Means within rows sharing the same letter do not differ significantly at $p=0.05$ (2-tailed test). $\mathrm{ns}=$ not significant

\begin{tabular}{|c|c|c|c|c|c|}
\hline & plant & diet & $\begin{array}{l}\text { diet } \\
+\mathrm{C}_{2} \mathrm{H}_{3} \mathrm{NaO}_{2}\end{array}$ & $\mathrm{~F}_{2,27}$ & LSD \\
\hline \multirow[t]{2}{*}{ mean aphid weight (mg) } & $0.398 \mathbf{a}$ & $0.297 \mathbf{b}$ & $0.379 \mathbf{a}$ & 3.92 & 0.080 \\
\hline & \pm 0.027 & \pm 0.028 & \pm 0.027 & $p<0.05$ & \\
\hline \multirow[t]{2}{*}{ ng EBF per aphid } & $21.976 \mathbf{a}$ & $15.327 \mathbf{b}$ & $20.71 \mathbf{a}$ & 3.85 & 5.222 \\
\hline & \pm 1.576 & \pm 1.725 & \pm 2.060 & $p<0.05$ & \\
\hline \multirow[t]{2}{*}{ ng EBF per mg aphid } & $56.187 \mathbf{a}$ & $51.883 \mathbf{a} \pm$ & $54.108 \mathbf{a} \pm$ & 0.237 & 9.973 \\
\hline & \pm 3.356 & 4.157. & 3.068 & ns & \\
\hline
\end{tabular}




\section{Legends for figures}

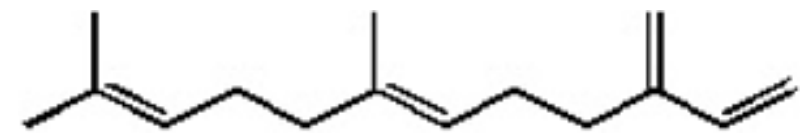

Fig. 1. (E)- $\beta$-farnesene (EBF).

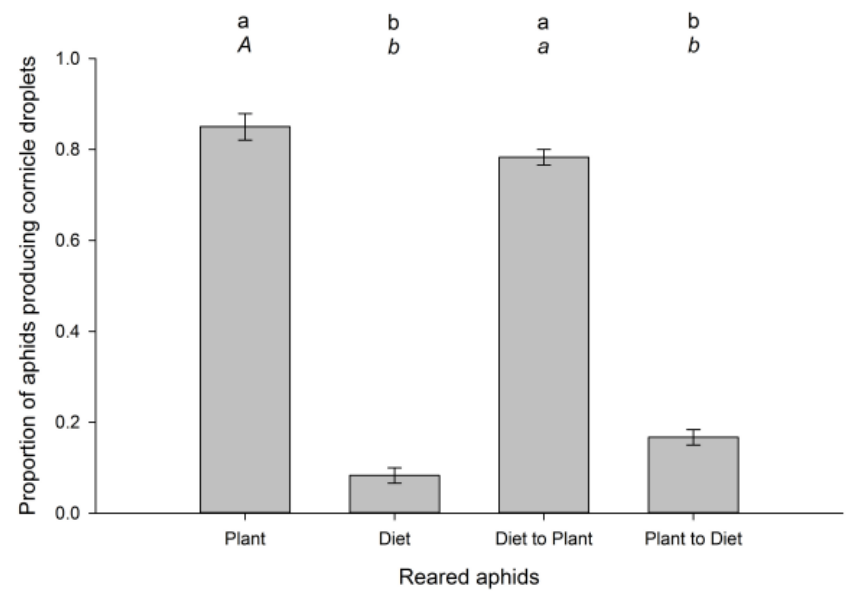

Fig. 2. Mean $(n=3)$ proportion of aphids producing cornicle droplets when stimulated following rearing on plants and artificial diet, and after transfer between these two substrates. Columns sharing the same letter do not differ significantly at $P=0.05$ (2-tailed test with LSD of 0.259 in the top row, and one-tailed test for a significant reduction from $A$ in italics with LSD of 0.206 in the lower row).

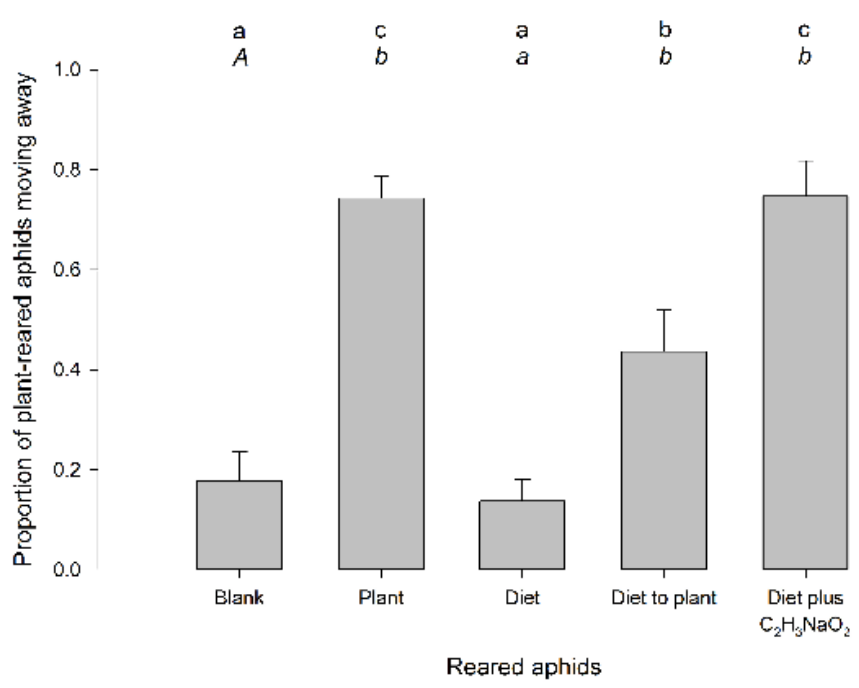

Fig. 3. Mean $(n=10)$ proportion of plant-reared aphids moving away from the cornicle secretion produced by aphids fed on different substrates. Columns sharing the same letter do not differ significantly at $P=0.05$ (2-tailed test with LSD of 0.180 in the top row, and one-tailed test for a significant reduction from $A$ in italics with LSD of 0.149 in the lower row). 


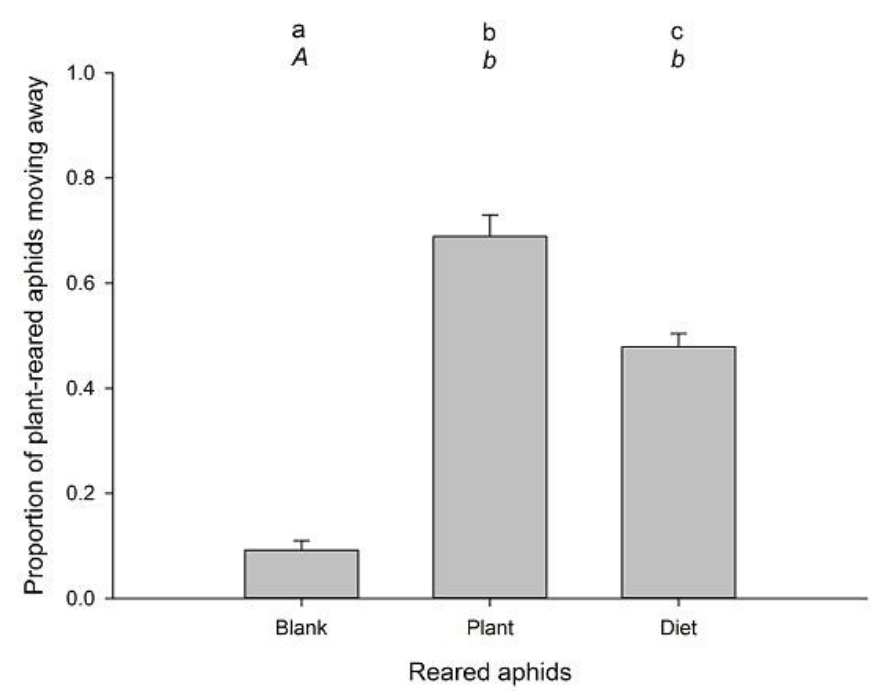

Fig. 4. Mean $(n=12)$ proportion of plant-reared aphids moving away from a punctured aphid, plant- or artificial diet-reared. Columns sharing the same letter do not differ significantly at $P=0.05$ (2-tailed test with LSD of 0.100 in the top row, and one-tailed test for a significant reduction from $A$ in italics with LSD of 0.066 in the lower row).

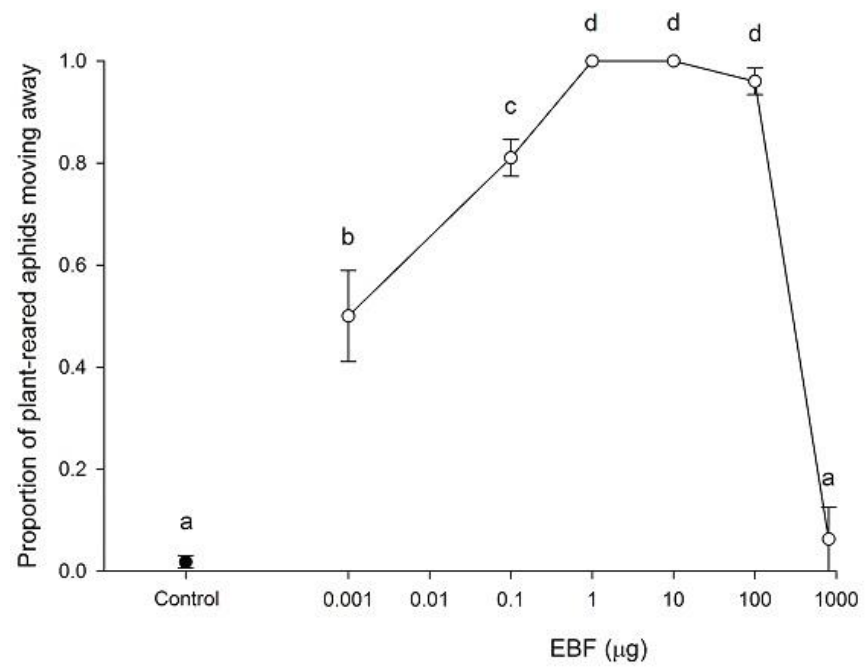

Fig. 5. Alarm response of colonies $(n=3-5)$ of $M$. persicae to synthetic $(E)-\beta$-farnesene in hexane and a hexane control. Columns with different letters indicate responses that are significantly different $(P<0.05)$. 